\title{
EDITORIAL
}

\section{LUNG Year in Review: 2021}

\author{
Peter V. Dicpinigaitis ${ }^{1}$
}

Accepted: 6 January 2022 / Published online: 18 January 2022

(c) The Author(s), under exclusive licence to Springer Science+Business Media, LLC, part of Springer Nature 2022

The end of 2021 marked the conclusion of the second year of service of the current Editor-in-Chief and Editorial Board of $L U N G$. Positive results achieved in 2020 were continued in 2021, as evidenced by an increasing number of article downloads and a rising journal impact factor. High-quality manuscripts were submitted by authors worldwide, resulting in an article acceptance rate of under $15 \%$.

In keeping with initially stated goals [1], we published ten State-of-the Art review articles in our six issues of 2021 [2-11]. State-of-the-Art reviews are comprehensive, up-todate reviews on specific topics contributed by experts in the field. Such articles are typically invited, however, outstanding, unsolicited reviews are also considered.

Among ongoing efforts at $L U N G$ is the enhancement of critical care content of the journal. To that end, we were pleased to publish a number of high-quality articles, including studies examining ventilator-induced lung injury [12], acute respiratory distress syndrome (ARDS) [13, 14], and weaning from non-invasive ventilation [15].

The year 2021 marked the second year of the COVID19 pandemic. Although the volume was not nearly as high as in 2020, SARS-CoV-2-related submissions in 2021 were many, but acceptances were few. In keeping with our policy of 2020 [16-19], accepted articles in 2021 were limited to those providing new and useful insights into COVID-19. Such contributions included a review of COVID-19 in children with asthma [2], post-COVID-19 chronic cough and other symptom burden [20-22], as well as evaluations of therapeutic interventions $[23,24]$ and comparison of mortality compared with seasonal influenza [25].

In keeping with historical precedent, $L U N G$ continues to give prominent attention to the important, and recently very active, field of cough. Indeed, 2022 promises to be a landmark year in the cough space, as we anticipate the

Peter V. Dicpinigaitis

pdicpin@gmail.com

1 Albert Einstein College of Medicine and Montefiore Medical Center/Einstein Division, 1825 Eastchester Road, Bronx, NY 10461, USA approval of the first-ever drug indicated for the treatment of refractory chronic cough [26, 27]. Cough-related articles published in 2021 examined post-COVID-19 cough [20, 22], clinical antitussive drug trials [28], and the importance of the placebo response [7], relevance of speech-language pathology interventions in chronic cough therapy [29, 30], cough monitoring [31], cough mechanisms, and diagnostic evaluation [32-39].

The field of lung cancer investigation continues to grow and represents a major focus in pulmonary medicine. $L U N G$ participated in the dissemination of evolving knowledge in this area by publishing a State-of-the-Art review on new developments in the diagnosis and management of smallcell lung cancer [10] in addition to a collection of articles examining lung cancer evaluation, therapy, complications, and survival [40-48].

Many contributions in the ever-expanding area of interventional pulmonology were received in 2021. The best of those studies investigated transthoracic needle aspiration [49], percutaneous lung biopsy [50], robotic-assisted [51] and 4D electromagnetic navigation bronchoscopy [52], transbronchial cryobiopsy [53, 54], and therapeutic intervention with endobronchial coils [55].

Interstitial lung disease (ILD) and idiopathic pulmonary fibrosis (IPF) remain subjects of active and increasing investigation. Reflecting this ongoing scientific production, $L U N G$ published two relevant State-of-the-Art reviews [3, 8 ] as well as a number of original investigations examining diagnosis [56-58], management [59], environmental and toxin-associated disease [60, 61], familial disease [62], and outcomes [63, 64].

The journal saw a number of submissions on the topic of sarcoidosis in 2021. The best of those contributions examined various aspects of the disease, including pharmacological therapy [65, 66], assessment [67], and clinical characteristics [68].

Obstructive airways disease was again well represented in the journal. An eclectic collection of published articles examined various aspects of chronic obstructive pulmonary disease and asthma [2, 11, 15, 31, 55, 64, 69-73]. 
The growing field of obstructive sleep apnea syndrome (OSAS) received due attention within the pages of $L U N G$ in 2021. In addition to a State-of-the-Art review on evaluation and management of adults with OSAS [4], clinical studies reported on associated comorbidities [74] and biomarkers [75]. Additional contributions included investigations of various aspects of pulmonary vascular disease [76, 77], lung transplantation [78, 79], pulmonary function testing [80], aspiration pneumonia [81], and vaping-associated conditions [82].

Our goal of featuring quality studies in pediatric pulmonology was fulfilled in 2021. In addition to a State-of-theArt review on COVID-19 in children with asthma [2], investigations in cystic fibrosis [83, 84] and pediatric cough [37] appeared in our pages. We continue to invite high-quality submissions in the field of pediatric respiratory medicine.

The vital area of translational research was well represented in the form of preclinical investigations examining a range of clinically relevant topics, including a State-ofthe-Art review on non-invasive measurement of pulmonary function [6], as well as studies involving $\beta-2$ adrenergic receptors [85, 86], pulmonary fibroblast cell growth [87], and hyperoxia-induced alveolar epithelial cell injury [88].

Throughout 2021, the editorial team at $L U N G$ worked in earnest to build on successes achieved in 2020. We strive to maintain a positive trajectory in the enhancement of the quality and impact of our journal. To that end, we will remain dependent on our colleagues worldwide, working in the laboratory and in the clinic, to contribute their quality work to $L U N G$.

\section{Declarations}

Conflict of interest Peter Dicpinigaitis, MD, is the Editor-in-Chief of $L U N G$. No other conflicts of interest related to the content of this editorial.

\section{References}

1. Dicpinigaitis PV (2021) LUNG year in review: 2020. Lung 199(1):1-5

2. Chatziparasidis G, Kantar A (2021) COVID-19 in children with asthma. Lung 199(1):7-12

3. Zaga V, Dell'Omo M, Murgia N, Mura M (2021) Tobacco worker's lung: a neglected subtype of hypersensitivity pneumonitis. Lung 199(1):13-19

4. Lee JJ, Sundar KM (2021) Evaluation and management of adults with obstructive sleep apnea syndrome. Lung 199(2):87-101

5. Saha BK, Chong WH (2021) Diffuse alveolar hemorrhage in cardiac diseases. Lung 199(2):103-112

6. Glaab T, Braun A (2021) Noninvasive measurement of pulmonary function in experimental mouse models of airway disease. Lung 199(3):255-261
7. Eccles R (2021) Placebo and side effects confound clinical trials on new antitussives. Lung 199(4):319-326

8. Banks DE, Morris MJ (2021) Inhalational constrictive bronchiolitis: the evolution of our understanding of this disease. Lung 199(4):327-334

9. Cleven KL, Rosenzvit C, Nolan A et al (2021) Twenty-year reflection on the impact of World Trade Center exposure on pulmonary outcomes in Fire Department of the City of New York (FDNY) rescue and recovery workers. Lung 199(6):569-578

10. Tariq S, Kim SY, de Oliveira M, Novaes J, Cheng H (2021) Update 2021: management of small cell lung cancer. Lung 199(6):579-587

11. Weissler JC, Adams TN (2021) Eosinophilic chronic obstructive pulmonary disease. Lung 199(6):589-595

12. He K, Han S, An L, Zhang J (2021) Inhibition of MicroRNA-214 alleviates lung injury and inflammation via increasing FGFR1 expression in ventilator-induced lung injury. Lung 199(1):63-72

13. Chalmers SJ, Lal A, Gajic O, Kashyap R (2021) Timing of ARDS resolution (TARU): a pragmatic clinical assessment of ARDS resolution in the ICU. Lung 199(5):439-445

14. Fan TH, Huang M, Gedansky A et al (2021) Prevalence and outcome of acute respiratory distress syndrome in traumatic brain injury: a systematic review and meta-analysis. Lung 199(6):603-610

15. Yu J, Lee M-R, Chen C-T et al (2021) Predictors of successful weaning from noninvasive ventilation in patients with acute exacerbation of chronic obstructive pulmonary disease: a single-center retrospective cohort study. Lung 199(5):457-466

16. Kerget B, Kerget F, Kocak AO et al (2020) Are serum interleukin 6 and surfactant protein D levels associated with the clinical course of COVID-19? Lung 198(5):777-784

17. Morgenthau AS, Levin MA, Freeman R et al (2020) Moderate or severe impairment in pulmonary function is associated with mortality in sarcoidosis patients infected with SARS-CoV-2. Lung 198(5):771-775

18. Scialo F, Daniele A, Amato F et al (2020) ACE2: the major cell entry receptor for SARS-CoV-2. Lung 198(6):867-877

19. Dicpinigaitis PV, Canning BJ (2020) Is there (will there be) a post-COVID-19 chronic cough? Lung 198(6):863-865

20. Sykes DL, Holdsworth L, Jawad N et al (2021) Post-COVID-19 symptom burden: what is long-COVID and how should we manage it? Lung 199(2):113-119

21. Dicpinigaitis PV (2021) Post-viral anosmia (loss of sensation of smell) did not begin with COVID-19! Lung 199(3):237-238

22. Fernandez-de-las-Penas C, Guijarro C, Plaza-Canteli S et al (2021) Prevalence of post-COVID-19 cough one year after SARSCoV-2 infection: a multicenter study. Lung 199(3):249-253

23. Selvaraj V, Khan MS, Bavishi C et al (2021) Tocilizumab in hospitalized patients with COVID-19: a meta analysis of randomized controlled trials. Lung 199(3):239-248

24. Cazzola M, Rogliani P, Salvi SS et al (2021) Use of thiols in the treatment of COVID-19: current evidence. Lung 199(4):335-343

25. Jeganathan N, Grewal S, Sathananthan M (2021) Comparison of deaths from COVID-19 and seasonal influenza in the USA (Letter to the Editor). Lung 199(5):559-561

26. Muccino DR, Morice AH, Birring SS et al (2020) Design and rationale of two phase 3 randomised controlled trials (COUGH-1 and COUGH-2) of gefapixant, a P2X3 receptor antagonist, in refractory or unexplained chronic cough. ERJ Open Res 6(4):00284-02020. https://doi.org/10.1183/23120541.00284-2020

27. Dicpinigaitis PV (2021) Coming soon: the first-ever drug(s) for refractory chronic cough. Lung 199(2):83-84

28. Morice AH, Birring SS, Smith JA et al (2021) Characterization of patients with refractory or unexplained chronic cough participating in a phase 2 clinical trial of the $\mathrm{P} 2 \mathrm{X} 3$-receptor antagonist gefapixant. Lung 199(2):121-129 
29. Slovarp LJ, Jette ME, Gillespie AI et al (2021) Evaluation and management outcomes and burdens in patients with refractory chronic cough referred for behavioral cough suppression therapy. Lung 199(3):263-271

30. Wright ML, Sundar KM, Herrick JS, Barkmeier-Kraemer JM (2021) Long-term treatment outcomes after behavioral speech therapy for chronic refractory cough. Lung 199(5):517-525

31. Crooks MG, den Brinker AC, Thackray-Nocera S et al (2021) Domiciliary cough monitoring for the prediction of COPD exacerbations. Lung 199(2):131-137

32. Park J-S, Burton L, Van der Wall H, Falk GL et al (2021) Modified reflux scintigraphy detects pulmonary microaspiration in severe gastro-esophageal and laryngopharyngeal reflux disease. Lung 199(2):139-145

33. (2021) Abstracts from the 2021 American Cough Conference. Lung 199(4):427-431. https://doi.org/10.1007/ s00408-021-00457-3

34. Morice AH (2021) On chronic cough diagnosis, classification, and treatment (Letter to the Editor). Lung 199(4):433-434

35. Koskela HO, Nurmi HM, Song W-J (2021) Deep inspiration-provoked cough: a sign of cough reflex arc hypersensitivity. Lung 199(5):501-505

36. Puente-Maestu L, Molina-Paris J, Trigueros JA et al (2021) A survey of physicians' perception of the use and effectiveness of diagnostic and therapeutic procedures in chronic cough patients. Lung 199(5):507-515

37. Anderson-James S, Newcombe PA, Marchant JM et al (2021) Children's acute cough-specific quality of life: revalidation and development of a short form. Lung 199(5):527-534

38. Gowan GM, Huffman M, Weiner M et al (2021) Management of chronic cough in adult primary care: a qualitative study (Letter to the Editor). Lung 199(5):563-568

39. Badri H, Satia I, Bansal V et al (2021) Heartburn as a marker of the success of acid suppression therapy in chronic cough. Lung 199(6):597-602

40. Magouliotis DE, Fergadi MP, Spiliopoulos K, Athanassiadi K (2021) Uniportal versus multiportal video-assisted thoracoscopic lobectomy for lung cancer: an updated meta-analysis. Lung 199(1):43-53

41. Voorn MJJ, Aerts LPA, Bootsma GP et al (2021) Associations of pretreatment physical status parameters with tolerance of concurrent chemoradiation and survival in patients with non-small cell lung cancer. Lung 199(2):223-234

42. Arndt AT, Brunelli A, Cicconi S et al (2021) Redefining the risk of surgery for clinical stage IIIA (N2) non-small cell lung cancer: a pooled analysis of the STS GTSD and ESTS registry. Lung 199(3):311-318

43. Fiorelli A, D’Andrilli A, Carlucci A et al (2021) Pulmonary hamartoma associated with lung cancer (PHALC Study): results of a multicenter study. Lung 199(4):369-378

44. Schlachtenberger G, Doerr F, Menghesha $\mathrm{H}$ et al (2021) A modified calculation improves the accuracy of predicted postoperative lung function values in lung cancer patients. Lung 199(4):395-402

45. Thomas GK, Trankle CR, Carbone S et al (2021) Diastolic dysfunction contributes to impaired cardiorespiratory fitness in patients with lung cancer and reduced lung function following chest radiation. Lung 199(4):403-407

46. Wankhede D, Grover S, Awendila L (2021) Left upper lobectomy for lung cancer as a risk factor for cerebral infarction: a systematic review and meta-analysis. Lung 199(5):535-547

47. Sibille A, Henket M, Corhay JL et al (2021) White blood cells in patients treated with programmed cell death-1 inhibitors for nonsmall cell lung cancer. Lung 199(5):549-557

48. Vayntrub Y, Gartman E, Nici L, Jankowich MD et al (2021) Diagnostic performance of the Herder Model in Veterans undergoing PET scans for pulmonary nodule evaluation. Lung 199(6):653-657

49. Willey D, Garcia-Saucedo J, Stancampiano F et al (2021) Safety and diagnostic yield of transthoracic needle aspiration of the lung in elderly patients. Lung 199(2):171-176

50. Rong E, Hirschl DA, Zalta B et al (2021) A retrospective multisite academic center analysis of pneumothorax and associated risk factors after CT-guided percutaneous lung biopsy. Lung 199(3):299-305

51. Benn BS, Romero AO, Lum M, Krishna G (2021) Roboticassisted navigation bronchoscopy as a paradigm shift in peripheral lung access. Lung 199(2):177-186

52. Patrucco F, Daverio M, Airoldi C et al (2021) 4D Electromagnetic navigation bronchoscopy for the sampling of pulmonary lesions: first European real-life experience. Lung 199(5):493-500

53. Deasy KF, Walsh LJ, Kennedy MP, Henry MT (2021) Endobronchial balloon blockers: a retrospective analysis of their implementation for use in transbronchial cryobiopsy under conscious sedation. Lung 199(2):187-193

54. Benn BS, Romero AO, Bawaadam H et al (2021) Cone beam CT guidance improves transbronchial lung cryobiopsy safety. Lung 199(5):485-492

55. Van Dijk M, Hartman JE, Augustijn SWS et al (2021) Comparison of multiple diagnostic tests to measure dynamic hyperinflation in patients with severe emphysema treated with endobronchial coils. Lung 199(2):195-198

56. Lang D, Akbari K, Horner A et al (2021) Computed tomography findings as determinants of local and systemic inflammation biomarkers in interstitial lung diseases: a retrospective registry-based descriptive study. Lung 199(2):155-164

57. Aoshima Y, Enomoto Y, Muto S et al (2021) Gremlin-1 for the differential diagnosis of idiopathic pulmonary fibrosis versus other interstitial lung diseases: a clinical and pathophysiological analysis. Lung 199(3):289-298

58. Xie T, Han L, Chen Y, Wu H (2021) Progranulin and activin A concentrations are elevated in serum from patients with acute exacerbations of idiopathic pulmonary fibrosis. Lung 199(5):467-473

59. Adams CJ, Chohan K, Rozenberg D et al (2021) Feasibility and outcomes of a standardized management protocol for acute exacerbation of interstitial lung disease. Lung 199(4):379-387

60. Lewin-Smith MR, Martinez A, Brooks DI, Franks TJ (2021) Pulmonary pathology diagnoses in the US Military during the global war on terrorism. Lung 199(4):345-355

61. Reese SW, Cone E, Marchese M et al (2021) Lessons from pharmacovigilance: pulmonary immune-related adverse events after immune checkpoint inhibitor therapy. Lung 199(2):199-211

62. Klay D, van der Vis JJ, Roothaan SM et al (2021) Connective tissue growth factor single nucleotide polymorphisms in (familial) pulmonary fibrosis and connective tissue disease associated interstitial lung disease. Lung 199(6):659-666

63. Hoffman TW, van Moorsel CHM, Kazemier KM et al (2021) Humoral immune status in relation to outcomes in patients with idiopathic pulmonary fibrosis. Lung 199(6):667-676

64. Zeba F, Yanning W, Melek J et al (2021) Prognostic significance of pulmonary artery to aorta ratio and other CT markers in pulmonary fibrosis with and without emphysema. Lung 199(6):677-680

65. Judson MA (2021) Corticosteroid-sparing drugs in sarcoidosis: how should we assess them? Lung 199(2):85-86

66. Friedman MA, Le B, Stevens J et al (2021) Tofacitinib as a steroid-sparing therapy in pulmonary sarcoidosis, an open-label prospective proof-of-concept study. Lung 199(2):147-153

67. Baughman RP, Kotzin J, Lower EE (2021) The value of a patient global assessment in management of sarcoidosis. Lung 199(4):357-362 
68. Alzghoul BN, Zayed Y, Obeidat A et al (2021) Clinical characteristics of sarcoidosis patients with self-reported lymphoma: a US nationwide registry study. Lung 199(6):611-618

69. Roig J, Domingo C, Burdon J, Michaelis S (2021) Irritant-induced asthma caused by aerotoxic syndrome. Lung 199(2):165-170

70. Yingchoncharoen P, Charoenngam N, Ponvilawan B et al (2021) The association between asthma and risk of myasthenia gravis: a systematic review and meta-analysis. Lung 199(3):273-280

71. Collaro AJ, Chang AB, Marchant JM et al (2021) Determinants and follow-up of lung function data from a predominantly First Nations cohort of adults referred to specialist respiratory outreach clinics in regional and remote Queensland. Lung 199(4):417-425

72. Su L, Zhao Q, Liu T et al (2021) Efficacy of high-flow nasal cannula oxygen therapy in patients with mild hypercapnia. Lung 199(5):447-545

73. Zhou Y, Qiao Y, Adcock IM et al (2021) FIZZ2 as a biomarker for acute exacerbation of chronic obstructive pulmonary disease. Lung 199(6):629-638

74. Allahwala UK, Cistulli PA, Dissanayake HU et al (2021) Influence of obstructive sleep apnea severity on coronary collateral recruitment during coronary occlusion. Lung 199(4):409-416

75. Tian Z, Xiao J, Kang J et al (2021) Effects of continuous positive airway pressure on cell adhesion molecules in patients with obstructive sleep apnea: a meta-analysis. Lung 199(6):639-651

76. Cook CM, Simpson SQ, Satterwhite L (2021) Excipient-induced pulmonary vascular disease: an underrecognized and deadly complication of opioid addiction. Lung 199(4):363-368

77. Koike H, Sueyoshi E, Nishimura T et al (2021) Effect of balloon pulmonary angioplasty on homogenization of lung perfusion blood volume by dual-energy computed tomography in patients with chronic thromboembolic pulmonary hypertension. Lung 199(5):475-483

78. Nascimento DZ, Watte G, Torres FS et al (2021) Utilization of quantitative computed tomography assessment to identify bronchiolitis obliterans syndrome after single lung transplantation. Lung 199(1):29-35

79. d'Alessandro M, Bergantini L, Fossi A et al (2021) The role of galectins in chronic lung allograft dysfunction. Lung 199(3):281-288
80. Sheshadri A, Keus L, Blanco D et al (2021) Pulmonary function testing in patients with tracheostomies: feasibility and technical considerations. Lung 199(3):307-310

81. Seo ZW, Min JH, Huh S et al (2021) Prevalence and severity of dysphagia using videofluoroscopic swallowing study in patients with aspiration pneumonia. Lung 199(1):55-61

82. Chen L, Arens R, Chidambaram AG et al (2021) Vaping associated pulmonary nontuberculous mycobacteria. Lung 199(1):21-27

83. Kasi AS, Wee CP, Keens TG, Salinas DB (2021) Abnormal lung clearance index in cystic fibrosis children with normal $\mathrm{FEV}_{1}$ and single-breath nitrogen washout test. Lung 199(1):37-41

84. Boonjindasup W, Chang AB, Marchant JM et al (2021) How many maneuvers should we do for maximal inspiratory and expiratory muscle pressure testing in children: a retrospective review in children with cystic fibrosis. Lung 199(2):213-222

85. Zheng Z, Cao B, Hu Y et al (2021) Spatiotemporal changes in the gene expression spectrum of the $\beta 2$ adrenergic receptor signaling pathway in the lungs of Rhesus monkeys. Lung 199(1):73-82

86. Zhang R-G, Niu Y, Pan K-W et al (2021) $\beta_{2}$-adrenoceptor activation stimulates IL-6 production via PKA, ERK1/2, Src, and betaarrestin 2 signaling pathways in human bronchial epithelia. Lung 199(6):619-627

87. Zeng Y, Yu J, Liu M et al (2021) Analyzing the effect of vitronectin on cell growth and mesenchymal-epithelial transition of pulmonary fibroblast cells. Lung 199(4):389-394

88. Yang M, Gao X-R, Meng Y-N et al (2021) ETS1 ameliorates hyperoxia-induced alveolar epithelial cell injury by regulating the TGM2-mediated Wnt/ $\beta$-catenin pathway. Lung 199(6):681-690

Publisher's Note Springer Nature remains neutral with regard to jurisdictional claims in published maps and institutional affiliations. 